\title{
Modeling Sociocultural Influences on Decision Making: Understanding Conflict, Enabling Stability. Edited by Joseph V. Cohn, Sae Schatz, Hannah Freeman, and David J. Y. Combs. Boca Raton, FL: CRC Press. 2017.
}

Nicole K. Drumhiller

American Public University System

Follow this and additional works at: https://digitalcommons.usf.edu/jss

pp. 119-121

\section{Recommended Citation}

Drumhiller, Nicole K.. "Modeling Sociocultural Influences on Decision Making: Understanding Conflict, Enabling Stability. Edited by Joseph V. Cohn, Sae Schatz, Hannah Freeman, and David J. Y. Combs. Boca Raton, FL: CRC Press. 2017.." Journal of Strategic Security 10, no. 2 (2017) : 119-121. DOI: http://doi.org/10.5038/1944-0472.10.2.1600 Available at: https://digitalcommons.usf.edu/jss/vol10/iss2/8

This Book Review is brought to you for free and open access by the Open Access Journals at Digital Commons @ University of South Florida. It has been accepted for inclusion in Journal of Strategic Security by an authorized editor of Digital Commons @ University of South Florida. For more information, please contact digitalcommons@usf.edu. 
Modeling Sociocultural Influences on Decision Making:

Understanding Conflict, Enabling Stability. Edited by Joseph V. Cohn, Sae Schatz, Hannah Freeman, and David J. Y. Combs. Boca Raton, FL: CRC Press. 2017. 


\section{Modeling Sociocultural Influences on Decision Making: Understanding Conflict, Enabling Stability. Edited by Joseph V. Cohn, Sae Schatz, Hannah Freeman, and David J. Y. Combs. Boca Raton, FL: CRC Press. 2017. ISBN: 978-1-4987-3669-5. Maps. Glossary. Sources Cited. Index. Pp. xiii-546. \$129.95.}

Modeling Sociocultural Influences on Decision Making is a collaborative volume that draws on expert knowledge from academia, government, and industry. Joseph Cohn has a Ph.D. in Neuroscience and a background in human performance enhancement. Sae Schatz, Ph.D., has a background in learning science and cognitive science, and is an applied human-systems researcher. Hannah Freeman has a background in international and comparative politics with a focus on conflict studies, and David J.Y. Combs has a Ph.D. in experimental social psychology. Together these editors draw from their collective backgrounds on human interaction and focus their work to better understanding political and social unrest in a manner that guides the reader from theme to theme.

The overarching goal of this book is to foster a better understanding of cross cultural behavior, and with that, sociocultural conflict. It does this with an assessment of the foundational question, "to what extent does the sociocultural environment in which an individual develops influence their decision making processes?” (xxv). The book begins with the assumption that positive social interactions result from a mutual understanding and an ability to predict the behavior of others. Along these lines the book "explores how advances in formation and social media technologies, combined with social science and modeling and simulation tools, can be leveraged to better understand sociocultural decision making processes, providing an alternative means for gaining a shared understanding in today's high-tech and globally interconnected world" (xxvi). With rapidly changing communication platforms that allow for near instantaneous communications, which are of varying reliability and credibility, this book is timely as policy makers and practitioners seek to better understand the impact that sociocultural influences have on decision making and behavior.

This book provides readers with a current look at the literature on crosscultural theories of human behavior and their application. The book is organized into four sections where the reader is taken on a journey that begins with theory building and data exploration and then moves forward in an application of those theories. From here the reader then moves into the 
development of sociocultural models which ultimately seeks to provide more insight and understanding of conflict stability. Section I, "Building Theories," draws on an overarching theory of culture, and hits on the subjects of individual-level information processing, social media analysis, and the spread of public opinion. In this section, culture and institutional norms are examined to explore the role they play in industrial and aviation accidents, and cultural narratives are explored to better understand how they influence the way people think about and interpret the world around them, and how they respond to threats.

Section II, "Collecting and Analyzing Data," looks at data collection in cross cultural societies and considers key ethical concerns for collecting data in conflict areas. The different data collection methods discussed include the use of high-risk ethnography and surveys, as well as data collection possibilities through social media and data collection apps. Section III, is focused on "Building and Validating Sociocultural Models," and section IV, "Applying Sociocultural Models to Gain Insight into Conflict and Instability," focuses on using sociocultural models to represent and understand the drives of conflict and instability. In this manner, the authors attempt to validate the theories presented through prediction efforts aimed at forecasting future operating environments.

One of the unique features of this work is the inclusion of a "use case" that centers on a fictional megacity which helps to bring the chapters together. The megacity of Xanadu helps depict what the world will face in the years to come as diverse urban populations continue to expand. With that expansion, one can expect some degree of social unrest and intergroup conflict to occur. The megacity use case allows each chapter to apply its insights in a meaningful manner that helps provide further continuity across the chapters.

This book has relevancy for those interested in intergroup conflict, human behavior, and decision making. From an intelligence standpoint, the book offers relevant insight into understanding cross cultural differences when it comes to individual and group behavior. Among the key questions explored include how one can assess the interests and intents of others, be they individuals, groups, or states, in a manner that mitigates our own biases. The authors utilize call out boxes to draw the reader's attention to key concepts, a useful feature for students. In addition, the authors end their chapters with a series of discussion questions, a useful feature for instructors and researchers to help generate further discussion on the concepts covered. Overall Cohn, 
Schatz, Freeman, and Combs have developed a relevant and thoughtprovoking book that is worth purchasing given its price point.

Nicole K. Drumhiller, American Public University System 